\title{
Oncological outcome of malignant colonic obstruction in the Dutch Stent-In 2 trial
}

\author{
D. A. M. Sloothaak ${ }^{1}$, M. W. van den Berg ${ }^{2}$, M. G. W. Dijkgraaf ${ }^{3}$, P. Fockens ${ }^{2}$, P. J. Tanis ${ }^{1}$, \\ J. E. van Hooft ${ }^{2}$ and W. A. Bemelman ${ }^{1}$ on behalf of the collaborative Dutch Stent-In study group \\ ${ }^{1}$ Department of Surgery, ${ }^{2}$ Department of Gastroenterology and Hepatology, and ${ }^{3}$ Clinical Research Unit, Academic Medical Centre, Amsterdam, \\ The Netherlands \\ Correspondence to: Professor W. A. Bemelman, Department of Surgery, Academic Medical Centre, PO Box 22660, 1100 DD Amsterdam, The Netherlands \\ (e-mail: w.a.bemelman@amc.uva.nl)
}

\begin{abstract}
Background: The Stent-In 2 trial randomized patients with malignant colonic obstruction to emergency surgery or stent placement as a bridge to elective surgery. The aim of this study was to compare the oncological outcomes.

Methods: Disease recurrence, and disease-free, disease-specific and overall survival were evaluated, including a subgroup analysis of patients with a stent- or guidewire-related perforation.

Results: Of 98 patients included in the original Stent-In 2 trial, patients with benign (16) or incurable (23) disease were excluded from this study, along with a patient who had withdrawn from the trial. Of the remaining 58 patients, 32 were randomized to emergency surgery ( 31 resection, 1 stoma only) and 26 to stenting. Unsuccessful stenting required emergency surgery in six patients owing to wire or stent perforation. Locoregional or distant disease recurrence developed in nine of 32 patients in the emergency surgery group and 13 of 26 in the stent group. Disease-free survival was worse in the subgroup with stentor guidewire-related perforation. Five of six patients in this subgroup developed a recurrence, compared with nine of 32 in the emergency surgery group and eight of 20 who had unperforated stenting.

Conclusion: Stent placement for malignant colonic obstruction was associated with a risk of recurrence in this trial, but the numbers are small. There is not enough evidence to refute the approach strongly. Registration number: ISRCTN46462267 (http://www.controlled-trials.com).
\end{abstract}

Presented to the spring meeting of the Association of Surgeons from the Netherlands, Veldhoven, The Netherlands, May 2013, and to United European Gastroenterology Week, Berlin, Germany, October 2013

Paper accepted 8 August 2014

Published online 9 October 2014 in Wiley Online Library (www.bjs.co.uk). DOI: 10.1002/bjs.9645

\section{Introduction}

Stenting malignant colonic obstruction as a bridge to elective surgery has become a widely used treatment option. Initial cohort studies ${ }^{1-4}$ suggested that the use of a stent was associated with lower mortality, morbidity and colostomy rates than emergency surgical intervention. Randomized trials thereafter showed conflicting results, and meta-analyses ${ }^{5}$ did not confirm a reduction in mortality or secondary stoma rate.

The Dutch Stent-In 2 randomized clinical trial (ISRCTN46462267) compared stenting as a bridge to surgery with emergency surgery. One of the potential complications of endoscopic stent placement in this trial was tumour perforation. The clinical stentor procedure-related perforation rate was 13 per cent
(6 of 47), and occult perforations were revealed in a further 10 per cent of the resected specimens $(3 \text { of } 31)^{6}$.

The possibility of tumour cell dissemination resulting from stent insertion and/or tumour perforations is worrying, and potential oncological consequences have been debated extensively ${ }^{7}$. Moreover, interest in potential tumour reactivity to stent placement is increasing ${ }^{8}$. In the present update of the Stent-In 2 trial, the impact of colonic stent placement as a bridge to elective surgery was assessed for oncological outcome in patients presenting with malignant colorectal obstruction.

\section{Methods}

Patients were identified from the database of the Stent-In 2 trial $^{9}$. The trial was stopped prematurely in March 2010 
in accordance with advice from the Data Safety Monitoring Board. Interim analysis of the first 60 included patients, and thereafter the first 90 patients, revealed an increased risk of 30-day morbidity (relative risk 1.60 (95 per cent c.i. 0.85 to 3.01$)$ and 1.62 (0.94 to 2.78$)$ respectively) for the stent group compared with the emergency surgery group. In addition, interim analysis recorded no difference in the primary outcome of the study, which was global health status. Details of the study design and short-term outcomes have been published previously ${ }^{6}$. Patients randomized to emergency surgery underwent resection of the primary tumour, with either primary anastomosis, temporary stoma or definitive stoma, at the discretion of the surgeon. Those randomized to stent placement received either an enteral Wallstent $^{\mathrm{TM}}$ (diameter $22 \mathrm{~mm}$; Boston Scientific, Marlborough, Massachusetts, USA) or a WallFlex ${ }^{\mathrm{TM}}$ colonic stent (diameter $25 \mathrm{~mm}$; Boston Scientific).

Patients with non-malignant obstruction, those in whom malignancy was not confirmed histopathologically and patients who were eventually treated with palliative intent were excluded from the present study. The decision regarding intentionally palliative or curative treatment was made during multidisciplinary team meetings. Patients with resectable liver metastasis were treated with curative intent.

\section{Follow-up and data collection}

In the Dutch Stent-In 2 trial, patients were initially followed for at least 6 months after randomization. Prospectively collected patient demographics, treatment characteristics and pathology reports were complemented retrospectively with data on adjuvant treatment, recurrence (locoregional recurrence or distant metastasis) and survival. Information was obtained from hospital medical records and general practitioners. The total follow-up was calculated from the date of randomization in the Stent-In 2 trial.

\section{Endpoints}

Endpoints of the study were overall and locoregional disease recurrence, disease-free survival (DFS), disease-specific survival (DSS) and overall survival after 4 years. Diagnosis of disease recurrence was based on radiological imaging or histopathological investigation. Locoregional recurrence was defined as intestinal, regional lymph node or peritoneal recurrence. DFS was defined as the time between resection of the primary tumour and the diagnosis of disease recurrence or death from any cause. DSS was defined as the time to cancer-specific death, and overall survival was defined as the time to death from any cause.

\section{Statistical analysis}

Data were analysed based on the on-treatment principle ${ }^{10}$. Continuous data are presented as median (i.q.r.) and were compared using the Mann-Whitney $U$ test. For dichotomous outcomes, the stent and emergency surgery groups were compared by means of $\chi^{2}$ or Fisher's exact test. The Kaplan-Meier method was used for survival analysis, with comparison between stent and emergency surgery groups using the log rank test. In addition, a subanalysis was performed of all patients who had a stent-related perforation within the stent group. Inclusion in this subgroup was based on the presence of tumour perforation on pathological examination; this included both clinical and subclinical perforations. Estimated survival rates are reported with

Table 1 Baseline characteristics of eligible patients

\begin{tabular}{|c|c|c|c|}
\hline & $\begin{array}{c}\text { Emergency } \\
\text { surgery } \\
(n=32)\end{array}$ & $\begin{array}{c}\text { Colonic } \\
\text { stent as } \\
\text { bridge to } \\
\text { surgery } \\
(n=26)\end{array}$ & $P \ddagger$ \\
\hline Age (years) ${ }^{\star}$ & $70(61-79)$ & $67(60-67)$ & $0.839 \S$ \\
\hline Sex ratio $(M: F)$ & $18: 14$ & $12: 14$ & $0.598 \mathrm{I}$ \\
\hline ASA fitness grade & & & 0.797 \\
\hline I & 11 & 8 & \\
\hline$\|$ & 16 & 16 & \\
\hline III & 4 & 2 & \\
\hline Not known & 1 & 0 & \\
\hline cTNM stage & & & 0.731 \\
\hline 1 & 0 & 0 & \\
\hline$\|$ & 11 & 7 & \\
\hline III & 10 & 9 & \\
\hline IV & 3 & 1 & \\
\hline Not known & 8 & 9 & \\
\hline Urgency of resection & & & - \\
\hline Acute & 31 & $6+$ & \\
\hline Elective & 1 & 20 & \\
\hline pTNM stage & & & 0.236 \\
\hline 1 & 0 & 0 & \\
\hline ॥ & 18 & 10 & \\
\hline III & 11 & 15 & \\
\hline IV & 3 & 1 & \\
\hline pT category & & & 0.311 \\
\hline 1 & 0 & 0 & \\
\hline 2 & 5 & 1 & \\
\hline 3 & 21 & 17 & \\
\hline 4 & 6 & 8 & \\
\hline Lymph node count ${ }^{\star}$ & $13(7-19)$ & $15(12-19)$ & $0.180 \S$ \\
\hline Positive lymph node count ${ }^{\star}$ & $2(1-8)$ & $3(1-7)$ & $0.508 \S$ \\
\hline Radical resection & 31 & 26 & 1.000 \\
\hline Adjuvant chemotherapy & 15 & 13 & $1.000 \mathrm{I}$ \\
\hline Follow-up (months) ${ }^{*}$ & $45(35-60)$ & $41(19-55)$ & 0.3738 \\
\hline
\end{tabular}

*Values are median (i.q.r.). †Insufficient deployment of inserted stent (1), inability to insert guidewire (3), suspicion of guidewire-induced perforation (2). ASA, American Society of Anesthesiologists. $\ddagger$ Fisher’s exact test, except $\$$ Mann-Whitney $U$ test and $\mathbb{I I} \chi^{2}$ test. 


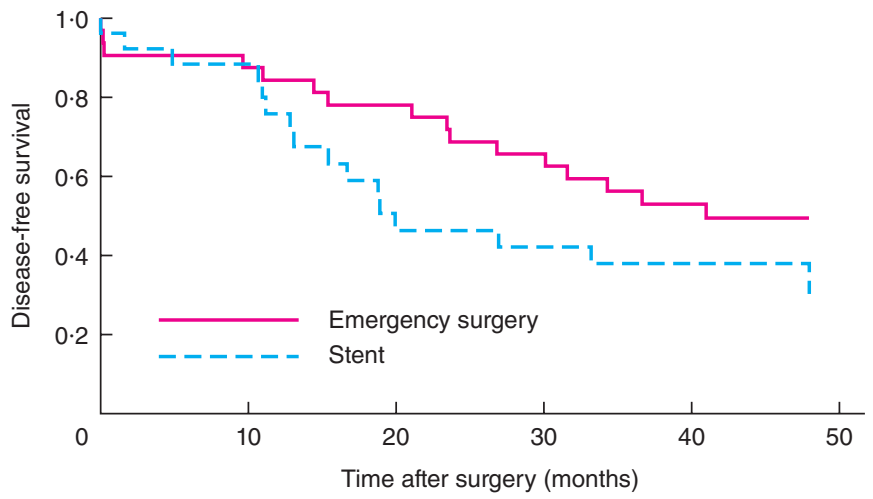

\begin{tabular}{|c|c|c|c|c|c|}
\hline o. at risk & & & & & \\
\hline Emergency surgery & 32 & 28 & 25 & 21 & 15 \\
\hline Stent & 26 & 21 & 13 & 10 & 9 \\
\hline
\end{tabular}

a Disease-free survival

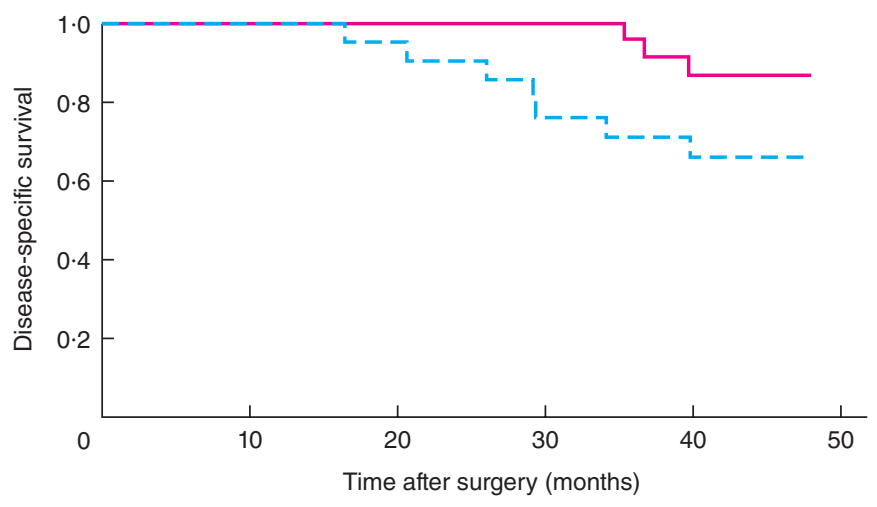

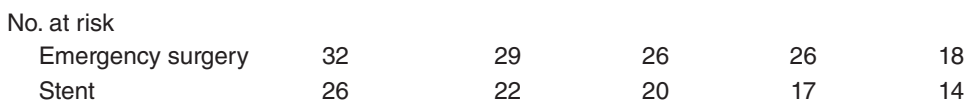

b Disease-specific survival

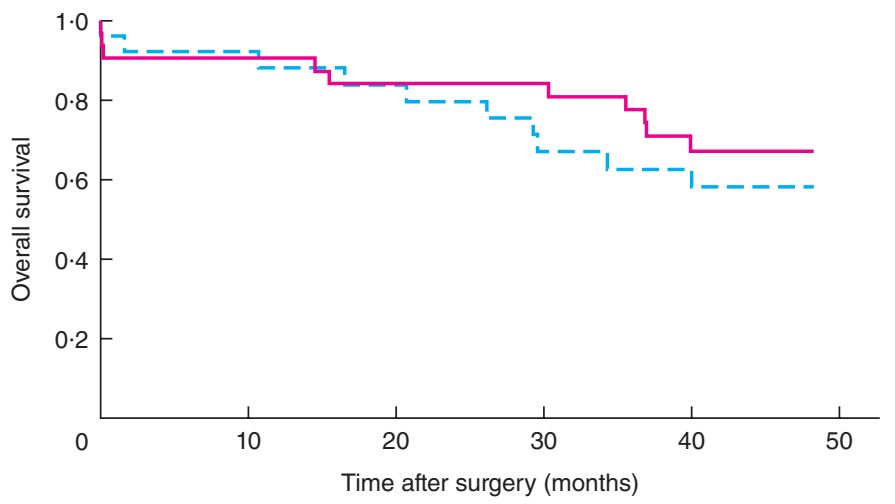

\begin{tabular}{|c|c|c|c|c|c|}
\hline Jo. at risk & & & & & \\
\hline Emergency surgery & 32 & 29 & 26 & 26 & 19 \\
\hline Stent & 26 & 22 & 20 & 16 & 13 \\
\hline
\end{tabular}

C Overall survival

Fig. 1 Kaplan-Meier survival curves for patients randomized to emergency surgery or colonic stenting: a disease-free survival, b disease-specific survival and c overall survival. a $P=0.149, \mathbf{b} P=0.061$ and $\mathbf{c} P=0.468$ (log rank test) 
95 per cent c.i. ${ }^{11}$. All tests were two-sided and $P<0 \cdot 050$ indicated statistical significance. Statistical analyses were performed with SPSS ${ }^{\circledR}$ for Windows ${ }^{\circledR}$ version 19.0 (IBM, Armonk, New York, USA).

\section{Results}

A total of 98 patients were included in the original Stent-In 2 trial between 2007 and $2009^{6}$. Thirty-nine patients were excluded from the present analysis because of benign disease (16) or palliative treatment ( 7 in whom the primary tumour was never resected, 9 with unresectable liver metastases, 4 with incurable peritoneal metastases, and 3 with distant metastases at multiple sites). One additional patient had withdrawn from the trial and was not included in the analysis. Characteristics of the 58 remaining patients are summarized in Table 1.

Six patients randomized to receive a stent as a bridge to surgery underwent emergency operation. In one of these patients the stent did not deploy well enough to result in clinical decompression. The guidewire could not be positioned in the lumen of the tumour, resulting in a false route in three patients and guidewire-induced perforation in two.

Stent-related perforations occurred in six of 26 patients in the stent group. Three stent-related perforations presented clinically (including 2 after complicated stent placement procedures) and a further three became apparent during pathological examination.

\section{Recurrence and survival}

Median follow-up was 45 (35-60) and 41 (19-55) months in the emergency surgery and stent groups respectively. Three of the 58 patients were lost to follow-up after 6-11 months.

A recurrence developed in nine of 32 patients after emergency surgery (2 locoregional recurrence, 7 distant metastasis) and in 13 of 26 patients after stent placement (5 locoregional metastasis, 8 distant metastasis).

The estimated 4-year DFS was 49 (95 per cent c.i. 32 to 67$)$ and 30 (10 to 51) per cent in the emergency surgery and stent groups respectively (Fig. 1a). Four-year DSS rates were 87 (73 to 100) and 66 (37 to 95) per cent respectively (Fig. 1b), and overall survival rates were 67 (50 to 84 ) and 58 (38 to 78) per cent (Fig. 1c).

For the subgroup analysis of stent-related perforations, endpoints were calculated separately for patients with (6) and without (20) stent-related perforation (Table 2).

Five of six patients developed a recurrence after a stent-related perforation (3 locoregional recurrence, 2 distant metastasis) compared with eight of 20 patients without
Table 2 Comparison of patients with and without stent perforation

\begin{tabular}{|c|c|c|c|}
\hline & $\begin{array}{c}\text { Stent } \\
\text { without } \\
\text { perforation } \\
(n=20)\end{array}$ & $\begin{array}{c}\text { Stent } \\
\text { perforation } \\
(n=6)\end{array}$ & $P \dagger$ \\
\hline Age (years) ${ }^{\star}$ & $66(58-79)$ & $81(69-85)$ & $0.046 \ddagger$ \\
\hline Sex ratio $(M: F)$ & $10: 10$ & $2: 4$ & 0.652 \\
\hline ASA fitness grade & & & 0.632 \\
\hline 1 & 6 & 2 & \\
\hline ॥ & 13 & 3 & \\
\hline III & 1 & 1 & \\
\hline cTNM stage & & & 0.309 \\
\hline 1 & 0 & 0 & \\
\hline II & 6 & 1 & \\
\hline III & 7 & 2 & \\
\hline IV & 0 & 1 & \\
\hline Not known & 7 & 2 & \\
\hline pTNM stage & & & 1.000 \\
\hline 1 & 0 & 0 & \\
\hline II & 8 & 2 & \\
\hline III & 11 & 4 & \\
\hline IV & 1 & 0 & \\
\hline Lymph node count ${ }^{\star}$ & $15(10-20)$ & $14(12-17)$ & $0.836 \ddagger$ \\
\hline Positive lymph node count ${ }^{\star}$ & $3(1-7)$ & $2(1-7)$ & $0.539 \div$ \\
\hline Adjuvant chemotherapy & 11 & 2 & 0.645 \\
\hline Follow-up (months) ${ }^{\star}$ & $43(22-54)$ & $29(12-57)$ & $0.533 \ddagger$ \\
\hline
\end{tabular}

*Values are median (i.q.r.). ASA, American Society of Anesthesiologists. $\dagger$ Fisher's exact test, except $\ddagger$ Mann-Whitney $U$ test.

stent-related perforation (2 locoregional metastasis, 6 distant metastasis).

The 4-year DFS rate was 0 (0 to 0$)$ per cent in patients with a stent-related perforation, and was worse than the rate of 45 (22 to 68) per cent in patients without stent-related perforation (Fig. 2a). DSS rates were $60(17$ to 100) and 69 (46 to 92) per cent respectively (Fig. 2b). The overall survival rate was 50 (10 to 90$)$ per cent for patients with a stent-related perforation and 62 (39 to 84) per cent among those without perforation (Fig. 2c).

\section{Discussion}

The results of this study are in line with data underlining concerns about potential negative oncological outcomes of colonic stent placement ${ }^{8,12-14}$. Examination of resected stented specimens showed that tumour and peritumoral ulceration occurred more frequently as a result of stents ${ }^{15}$. In addition, tumour manipulation during guidewire insertion, dilatation and stent deployment can cause disruption with potential spread of cancer cells (or their shed particles $)^{7}$. Only two of the six patients with stent-related perforation in the present study received adjuvant systemic chemotherapy. Although it is unknown whether adjuvant systemic chemotherapy is able to prevent outgrowth of 


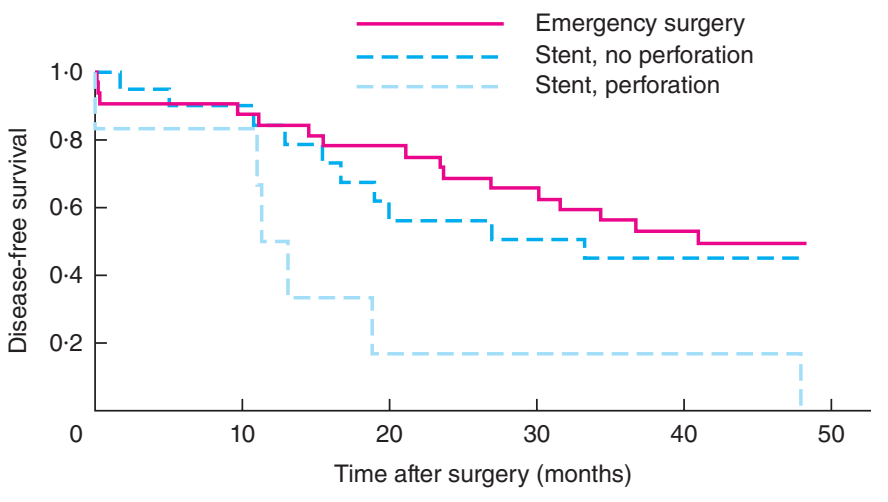

No. at risk

Emergency surgery

Stent, no perforation

Stent, perforation

$\begin{array}{ccccc}32 & 28 & 25 & 21 & 15 \\ 20 & 16 & 12 & 9 & 8 \\ 6 & 5 & 1 & 1 & 1\end{array}$

a Disease-free survival

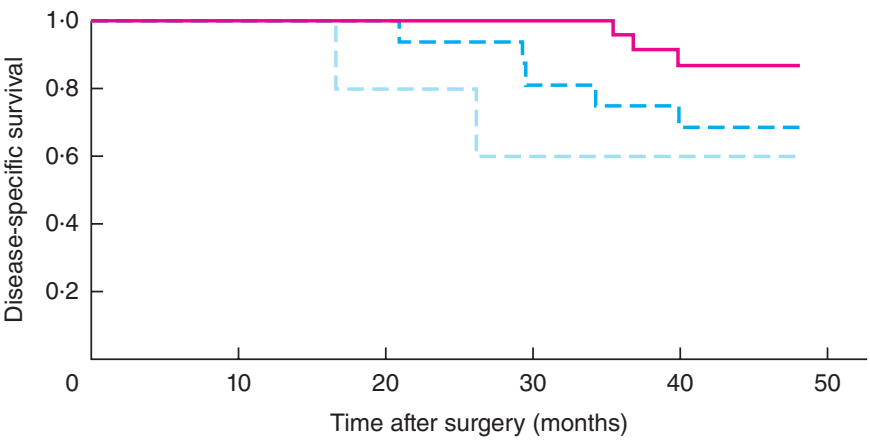

No. at risk

Emergency surgery

Stent, no perforation

Stent, perforation

$\begin{array}{ccccc}32 & 29 & 26 & 26 & 18 \\ 20 & 17 & 16 & 14 & 12 \\ 6 & 5 & 4 & 3 & 2\end{array}$

b Disease-specific survival
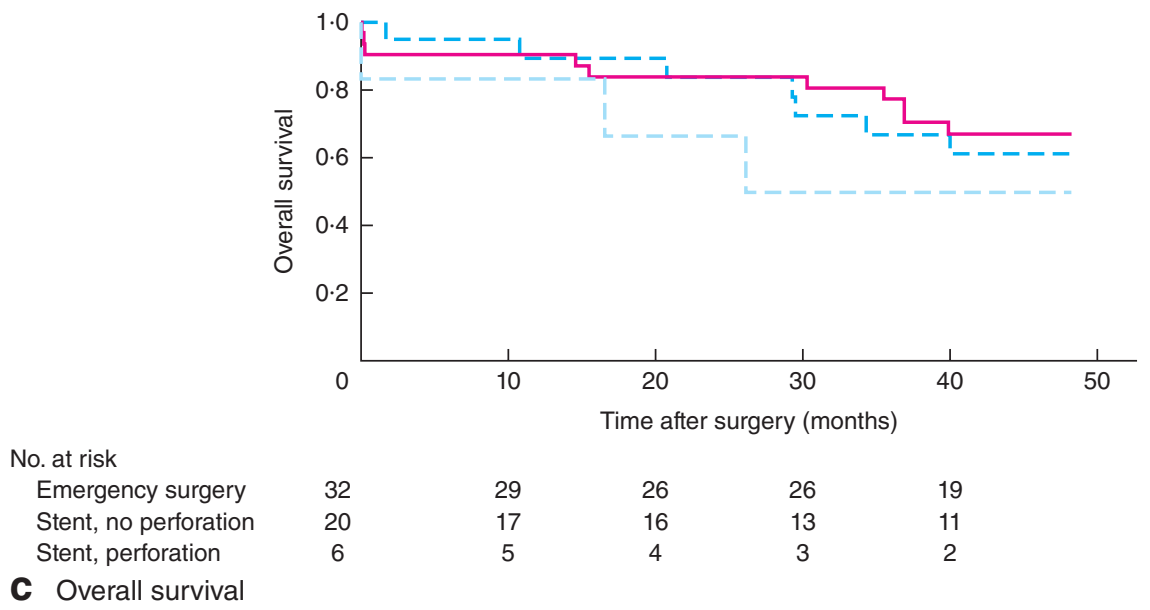

C Overall survival

Fig. 2 Kaplan-Meier survival curves for patients in the emergency surgery group and those who had colonic stenting with or without perforation: a disease-free survival, b disease-specific survival and $\mathbf{c}$ overall survival. a $P=0 \cdot 007, \mathbf{b} P=0 \cdot 099$ and $\mathbf{c} P=0 \cdot 478$ (log rank test) 
direct tumour spread after perforation, this may have influenced the overall recurrence rate ${ }^{16}$.

Literature on the oncological consequences of colonic stent placement in the curative setting is scarce. Recently, cohort studies have compared the oncological outcome of stenting as a bridge to surgery with emergency surgery. The group from St Vincent's University Hospital in Dublin $^{12}$ showed similar overall and cancer-specific survival in 49 patients. This has been echoed by others ${ }^{17}$, but there have also been reports of a negative impact on cancer outcomes. One retrospective study ${ }^{8}$ used a propensity score to adjust for allocation bias in 48 patients who received a bridging stent and 39 who underwent emergency surgery. The 5-year overall survival rate was significantly lower in the stent group than in the emergency surgery group ( 25 versus 62 per cent respectively) and the 5 -year cancer specific mortality rate was significantly higher in the stent group (48 versus 21 per cent). Finally, in another study ${ }^{14}$ of patients aged 75 years or younger, 38 of whom were stented and 24 had emergency surgery, the local recurrence-free survival rate was significantly worse after stenting ( 8 versus 32 per cent; $P=0 \cdot 038$ ).

The prevalence of stent-related complications is likely to be underestimated, because subclinical perforations may be identified only at the time of pathological examination ${ }^{18-20}$. The prevalence of clinical stent-related perforation is 6.9 per cent based on meta-analysis ${ }^{5}$. The risk of perforation may be related to local anatomy, tumour factors (length and constitution), stent design and experience of the clinician placing the stent $t^{1,18,21-23}$. Because it is still not clear how stent-related perforations can be prevented, this risk should be given serious consideration in clinical decision-making. Even if stent placement seems to be uncomplicated clinically, tumour biology may be altered owing to the mechanical stress, and tumour spillage may occur because of tumour disruption. A Markov chain Monte Carlo decision analysis model determined differences in effectiveness and costs between the two strategies for different patient scenarios based on perioperative risk factors ${ }^{24}$. Probabilities of outcome variables were based on systematic review of 54 studies including 1198 patients. Based on this analysis, the authors concluded that the benefits of colonic stenting are modest in low-risk patients, and may not outweigh the risks. Therefore, emergency surgery is probably the preferred treatment strategy for patients without significantly increased operative risk. On the other hand, stenting is probably the preferred strategy in patients at increased operative risk (age above 70 years, American Society of Anesthesiologists fitness grade III or more). The potentially impaired oncological outcome related to the risk of stent-related perforation seems to become less important than the increased risk of postoperative death in these frail patients.

\section{Collaborators}

Members of the Dutch Stent-In study group are collaborators in this study: J. E. van Hooft, P. Fockens, W. A. Bemelman, M. G. Dijkgraaf, M. A. Sprangers, C. J. Buskens (Academic Medical Centre, Amsterdam); J. M. Jansen, M. F. Gerhards (Onze Lieve Vrouwe Gasthuis, Amsterdam); R. Timmer, B. van Ramshorst (St Antonius Hospital, Nieuwegein); B. Oldenburg, R. van Hilligersberg (University Medical Centre, Utrecht); C. M. Bakker, M. Sosef (Atrium Hospital, Heerlen); P. Witteman, P. Kruyt (Gelderse Vallei Hospital, Ede); W. R. ten Hove, L. N. Tseng (Groen Hart Hospital, Gouda); K. van der Linde, S. A. Koopal (Medical Centre Leeuwarden, Leeuwarden); A. W. Marinelli, L. Perk (Medical Centre Haaglanden, Den Haag); M. F. Lutke Holzik (Medisch Spectrum Twente, Enschede); M. J. Grubben, J. Heisterkamp (Sint Elisabeth Hospital, Tilburg); A. C. Depla, E. Derksen (Slotervaart Hospital, Amsterdam); A. H. Naber, A. A. van Geloven (TerGooi Hospitals, Hilversum); R. Breumelhof, P. H. Davids (Diakonessenhuis, Utrecht); H. Akol, E. van der Zaag (Gelre Hospitals, Apeldoorn); E. Schenk, G. A. Patijn (Isala Hospitals, Zwolle); R. A. Veenendaal, R. A. Tollenaar (Leiden University Medical Centre, Leiden); A. van Berkel (Rode Kruis Hospital, Beverwijk); L. P. Gilissen, G. A. Nieuwenhuijzen (Catharina Hospital, Eindhoven); L. A. van der Waaij, P. C. Baas (Martini Hospital, Groningen); H. Cense (Rode Kruis Hospital, Beverwijk); P. Scholten, B. van Wagensveld (St Lucas Andreas Hospital, Amsterdam); J. J. Koornstra, K. Havenga (University Medical Centre Groningen, Groningen); M. van Milligen de Wit, A. M. Rijken (Amphia Hospital, Breda); M. Cazemier, O. R. Guicherit (Bronovo Hospital, Den Haag); M. H. Houben, W. H. Steup (Haga Hospitals, Den Haag).

\section{Disclosure}

The authors declare no conflict of interest.

\section{References}

1 Saida Y, Sumiyama Y, Nagao J, Uramatsu M. Long-term prognosis of preoperative 'bridge to surgery' expandable metallic stent insertion for obstructive colorectal cancer: comparison with emergency operation. Dis Colon Rectum 2003; 46(Suppl): S44-S49.

2 Martinez-Santos C, Lobato RF, Fradejas JM, Pinto I, Ortega-Deballón P, Moreno-Azcoita M. Self-expandable stent before elective surgery $v$ s. emergency surgery for the 
treatment of malignant colorectal obstructions: comparison of primary anastomosis and morbidity rates. Dis Colon Rectum 2002; 45: 401-406.

$3 \mathrm{Ng} \mathrm{KC,} \mathrm{Law} \mathrm{WL,} \mathrm{Lee} \mathrm{YM,} \mathrm{Choi} \mathrm{HK,} \mathrm{Seto} \mathrm{CL,} \mathrm{Ho} \mathrm{JW.}$ Self-expanding metallic stent as a bridge to surgery versus emergency resection for obstructing left-sided colorectal cancer: a case-matched study. 7 Gastrointest Surg 2006; 10: 798-803.

4 Park JS, Kim BG, Chang IT, Choi YS, Kwak BK, Shim HJ et al. Placement of stents in proximal colonic obstructions using a percutaneous retroperitoneal colostomy. Surg Laparosc Endosc Percutan Tech 2009; 19: e202-e205.

5 Tan CJ, Dasari BV, Gardiner K. Systematic review and meta-analysis of randomized clinical trials of self-expanding metallic stents as a bridge to surgery versus emergency surgery for malignant left-sided large bowel obstruction. $\mathrm{Br}$ 7 Surg 2012; 99: 469-476.

6 van Hooft JE, Bemelman WA, Oldenburg B, Marinelli AW, Lukte Holzik MF, Grubben MJ et al. Colonic stenting versus emergency surgery for acute left-sided malignant colonic obstruction: a multicentre randomised trial. Lancet Oncol 2011; 12: 344-352.

7 Maruthachalam K, Lash GE, Shenton BK, Horgan AF. Tumour cell dissemination following endoscopic stent insertion. Br 7 Surg 2007; 94: 1151-1154.

8 Sabbagh C, Browet F, Diouf M, Cosse C, Brehant O, Bartoli $\mathrm{E}$ et al. Is stenting as 'a bridge to surgery' an oncologically safe strategy for the management of acute, left-sided, malignant, colonic obstruction? A comparative study with a propensity score analysis. Ann Surg 2013; 258: 107-115.

9 van Hooft JE, Bemelman WA, Breumelhof R, Siersema PD, Kruyt PM, van der Linde $\mathrm{K}$ et al. Colonic stenting as bridge to surgery versus emergency surgery for management of acute left-sided malignant colonic obstruction: a multicenter randomized trial (Stent-in 2 study). BMC Surg 2007; 7: 12.

10 Chêne G, Morlat P, Leport C, Hafner R, Dequae L, Charreau I et al. Intention-to-treat $v s$. on-treatment analyses of clinical trial data: experience from a study of pyrimethamine in the primary prophylaxis of toxoplasmosis in HIV-infected patients. ANRS 005/ACTG 154 Trial Group. Control Clin Trials 1998; 19: 233-248.

11 Twisk JWR. Inleiding in de Toegepaste Biostatistiek (2nd edn). Elsevier: Amsterdam, 2010.

12 Kavanagh DO, Nolan B, Judge C, Hyland JM, Mulcahy $\mathrm{HE}$, O'Connell PR et al. A comparative study of short- and medium-term outcomes comparing emergent surgery and stenting as a bridge to surgery in patients with acute malignant colonic obstruction. Dis Colon Rectum 2013; 56: $433-440$.

13 Kim JS, Hur H, Min BS, Sohn SK, Cho CH, Kim NK.
Oncologic outcomes of self-expanding metallic stent insertion as a bridge to surgery in the management of left-sided colon cancer obstruction: comparison with nonobstructing elective surgery. World F Surg 2009; 33 : $1281-1286$.

14 Gorissen KJ, Tuynman JB, Fryer E, Wang L, Uberoi R, Jones $\mathrm{OM}$ et al. Local recurrence after stenting for obstructing left-sided colonic cancer. Br F Surg 2013; 100: 1805-1809.

15 Sabbagh C, Chatelain D, Trouillet N, Mauvais F, Bendjaballah S, Browet F et al. Does use of a metallic colon stent as a bridge to surgery modify the pathology data in patients with colonic obstruction? A case-matched study. Surg Endosc 2013; 27: 3622-3631.

16 Benson AB III, Schrag D, Somerfield MR, Cohen AM, Figueredo AT, Flynn PJ et al. American Society of Clinical Oncology recommendations on adjuvant chemotherapy for stage II colon cancer. 7 Clin Oncol 2004; 22: 3408-3419.

17 Kim HJ, Huh JW, Kang WS, Kim CH, Lim SW, Joo YE et al. Oncologic safety of stent as bridge to surgery compared to emergency radical surgery for left-sided colorectal cancer obstruction. Surg Endosc 2013; 27: 3121-3128.

18 Baron TH. Colonic stenting: technique, technology, and outcomes for malignant and benign disease. Gastrointest Endosc Clin N Am 2005; 15: 757-771.

19 Small AJ, Coelho-Prabhu N, Baron TH. Endoscopic placement of self-expandable metal stents for malignant colonic obstruction: long-term outcomes and complication factors. Gastrointest Endosc 2010; 71: 560-572.

20 Watt AM, Faragher IG, Griffin TT, Rieger NA, Maddern GJ. Self-expanding metallic stents for relieving malignant colorectal obstruction: a systematic review. Ann Surg 2007; 246: 24-30.

21 Binkert CA, Ledermann H, Jost R, Saurenmann P, Decurtins M, Zollikofer CL. Acute colonic obstruction: clinical aspects and cost-effectiveness of preoperative and palliative treatment with self-expanding metallic stents - a preliminary report. Radiology 1998; 206: 199-204.

22 Khot UP, Lang AW, Murali K, Parker MC. Systematic review of the efficacy and safety of colorectal stents. $\operatorname{Br} \mathcal{F}$ Surg 2002; 89: 1096-1102.

23 van Halsema EE, van Hooft JE, Small AJ, Baron TH, García-Cano J, Cheon JH et al. Perforation in colorectal stenting: a meta-analysis and a search for risk factors. Gastrointest Endosc 2014; 79: 970-982.e7.

24 Govindarajan A, Naimark D, Coburn NG, Smith AJ, Law $\mathrm{CH}$. Use of colonic stents in emergent malignant left colonic obstruction: a Markov chain Monte Carlo decision analysis. Dis Colon Rectum 2007; 50: 1811-1824. 